\title{
УДК 636.082.2
}

\section{Слюсаренко Ю.Л.}

асистентка

E-mail : slyusarenko.yulya@email.ua

кафедра технологій виробництва продукиії тваринництва

Житомирський національний агроекологічний університет

Житомир, Украӥна

\section{ВПЛИВ ТИПУ ВИЩОЇ НЕРВОВОЇ ДІЯЛЬНОСТІ НА РОБОЧУ ПРОДУКТИВНІСТЬ ТА РІСТ КОНЕЙ}

\begin{abstract}
Анотація
Дослідження присвячене вивченню впливу типу ВНД на формування рівня робочої продуктивність коней, основних промірів та живої маси .

Дослідження проводилось на поголів'ї коней украӥнської верхової породи племінного заводу ПрАТ «Райз-Максимко» (N=77). Походження коней визначали, виходячи з племінних карток. Аналіз робочої продуктивності коней відбувався на основі результатів заводських випробувань в господарстві. Визначення типу ВНД проводили за спрощеною методикою ВНДІК, а дані опраџьовано за методами варіаційної статистики

Проведено аналіз впливу типу ВНД на формування робочої продуктивності коней, ӥх відносний ріст та розвиток.

За результатами досліджень виявлено, щуо коні украӥнської верхової породи сильного врівноваженого рухливого та інертного типів ВНД за живою масою, приростами та робочою продуктивністю дещз переважають коней украӥнської верхової породи сильного неврівноваженого та сильного врівноваженого інертного типів ВНД у всі періодах вирощування.
\end{abstract}

Ключові слова: коні, тип ВНД, жива маса, ріст, індекси, проміри.

Вступ. Оцінка робочої продуктивності коней спортивних порід в ранньому віці має велике селекційне та економічне значення. В результаті випробувань проводиться оцінка жеребців-плідників та маток за якістю потомства, корегується селекційна робота зі спортивними породами, підвищується тиск добору за основними селекційними ознаками, особливо за показниками роботоздатності і тим самим прискорюється прогрес в породах, підвищується генетичний потенціал та іï конкурентоспроможність на міжнародному рівні. Науково доведено користь випробувань спортивних коней у ранньому віці. Так, за результатами багаторічних випробувань молодняку коней спортивних порід встановлено, що коні, високо оцінені на випробуваннях з вірогідністю на $84,5 \%$ на високому рівні виступають у спортивних турнірах $[1,2,3]$.

Метою наших досліджень було вивчення впливу типу ВНД на формування рівня робочої продуктивність коней, основних промірів та живої маси.

Методологія дослідження. Дослідження було проведено на поголів’ї коней української верхової породи племінного заводу ПрАТ «Райз-Максимко» (N=77).

Оцінка росту та розвитку проводилась за такими показниками: висота в холці, обхват грудей, коса довжина тулуба, обхват п'ястка та живою масою.

Аналіз робочої продуктивності коней відбувався на основі результатів заводських випробувань в господарстві.

Для вирішення поставленої мети використовували загальноприйняті зоотехнічні методи. Походження коней визначали виходячи з племінних карток. Визначення типу ВНД проводили за спрощеною методикою ВНДІК [4]. Усі дані статистично опрацьовано за методами варіаційної статистики [8].

С Слюсаренко Ю.Л., 2019 
Подільський вісник: сільське господарство, техніка, економіка
Podilian Bulletin: agriculture, engineering, economics

Результати. Для аналізу показників екстер'єру було відібрано 77 коней української верхової породи, яке було розподілене на 4 групи за типом вищої нервової діяльності. За результатами проведеного дослідження росту та розвитку коней.

Доросле поголів'я коней зі слабким типом ВНД за висотою в холці, косою довжиною тулуба та обхватом грудей вірогідно перевищують стандарт породи відповідно на 2, 5 та 4 см $(\mathrm{P}<0,01)$. Найнижчі показники за показником висоти в холці спостерігалися у дорослих коней 3-х інших груп (164 см).

Молодняк за промірами, перевищує стандарт за 4-ма показникам у 3-х група (сильний врівноважений інертний, сильний неврівноважений та слабкий) відповідно на 5, $4,8,7,16,11,1,25$ та 2,2 см. А коні з сильним врівноваженим рухливим типом ВНД, перевищують стандарт за косою довжиною, обхватом грудей та п'ястка на 1, 8 та 0,7 см.

Таблиця 1 - Жива маса коней по періодах вирощування, кг

\begin{tabular}{|c|c|c|c|c|}
\hline \multirow{2}{*}{ Вік } & \multicolumn{3}{|c|}{ Типи ВНД } \\
\cline { 2 - 5 } & $\begin{array}{c}\text { срільний } \\
\text { рухливий } \\
(\mathrm{n}=15)\end{array}$ & $\begin{array}{c}\text { сильний врівноважений } \\
\text { інертний } \\
(\mathrm{n}=11)\end{array}$ & $\begin{array}{c}\text { сильний неврівноважений } \\
(\mathrm{n}=37)\end{array}$ & $\begin{array}{c}\text { слабкий } \\
(\mathrm{n}=10)\end{array}$ \\
\hline 6 міс. & $276 \pm 6,6$ & $167 \pm 0,5$ & $115 \pm 5,11$ & $179 \pm 0,5$ \\
\hline 12 міс & $381 \pm 2,5$ & $301 \pm 1,6$ & $340 \pm 7,2$ & $315 \pm 6,0$ \\
\hline 18 міс. & $336 \pm 2,4$ & $330 \pm 1,7$ & $380 \pm 7,6$ & $325 \pm 6,2$ \\
\hline 24 міс. & $894 \pm 2,6$ & $462 \pm 1,8$ & $344 \pm 9,3$ & $463 \pm 6,7$ \\
\hline 30 міс. & $470 \pm 1,6$ & $475 \pm 1,8$ & $450 \pm 9,3$ & $438 \pm 6,8$ \\
\hline 42 міс. & $551 \pm 4,5$ & $447 \pm 4,1$ & $427 \pm 1,2$ & $501 \pm 59$ \\
\hline 54 міс. & $576 \pm 3,1$ & $587 \pm 4,3$ & $549 \pm 1,4$ & \\
\hline
\end{tabular}

Як видно 3 даних таблиці 1, коні української верхової породи сильного врівноваженого рухливого типів ВНД за живою масою та приростами дещо переважають коней сильного неврівноваженого та сильного врівноваженого інертного типів ВНД у всі періоди вирощування. Це вказує на неповноцінність годівлі та недостатній рівень фізичних навантажень для даних коней.

Дані таблиці 2 також підтверджують вищевказаний висновок.

Таблиця 2 - Проміри та індекси будови тіла коней різного типу ВНД

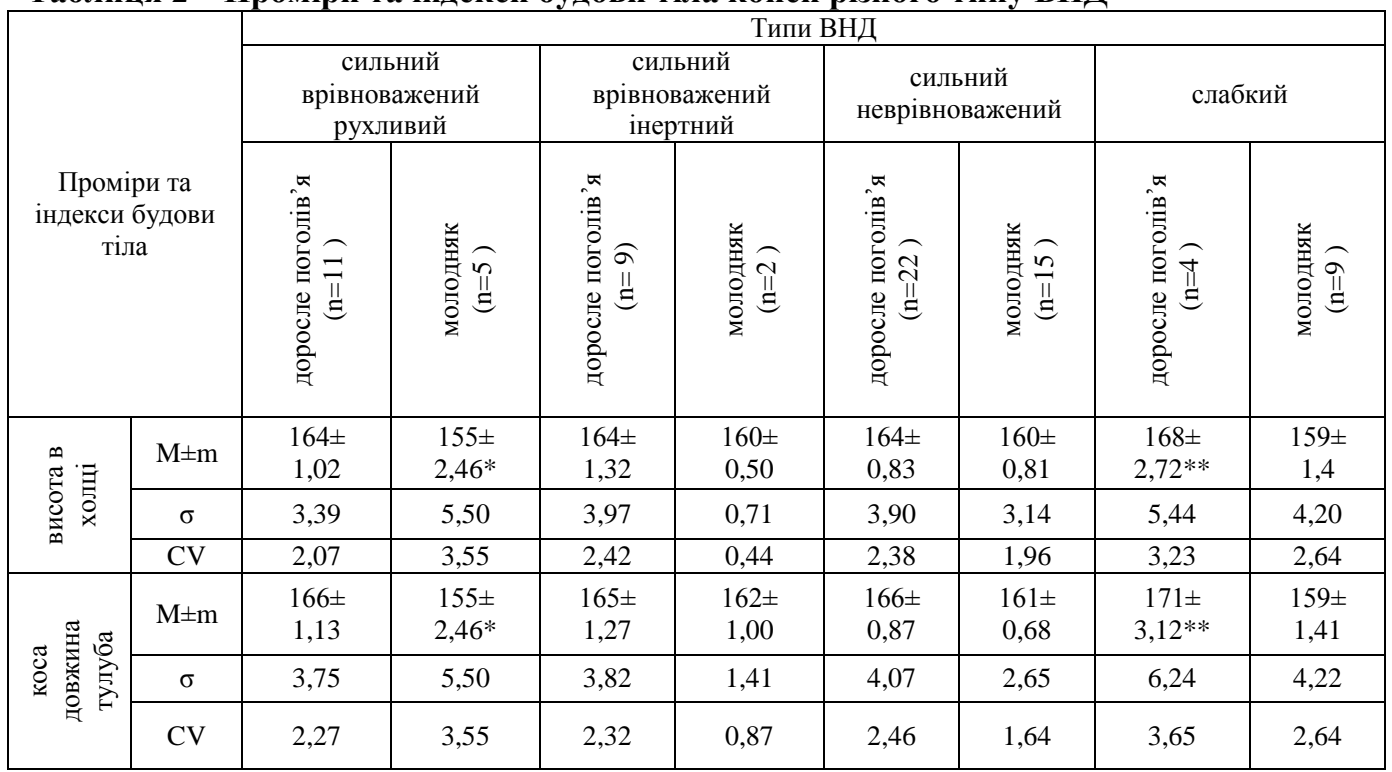


Продовження табл. 2

\begin{tabular}{|c|c|c|c|c|c|c|c|c|c|}
\hline \multirow{3}{*}{ 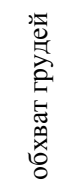 } & $\mathrm{M} \pm \mathrm{m}$ & $\begin{array}{c}194 \pm \\
1,92\end{array}$ & $\begin{array}{c}176 \pm \\
0,30\end{array}$ & $\begin{array}{c}194 \pm \\
1,50\end{array}$ & $\begin{array}{c}184 \pm \\
0,50\end{array}$ & $\begin{array}{c}194 \pm \\
1,33\end{array}$ & $\begin{array}{c}184 \pm \\
1,41\end{array}$ & $\begin{array}{c}198 \pm \\
3,07^{* * *}\end{array}$ & $\begin{array}{l}179 \pm \\
2,2^{*}\end{array}$ \\
\hline & $\sigma$ & 6,36 & 8,09 & 4,49 & 0,71 & 6,24 & 5,48 & 6,14 & 6,64 \\
\hline & $\mathrm{CV}$ & 3,28 & 4,60 & 2,32 & 0,39 & 3,21 & 2,98 & 3,11 & 3,71 \\
\hline \multirow{3}{*}{ 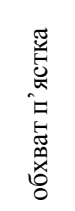 } & $\mathrm{M} \pm \mathrm{m}$ & $21 \pm 0,20$ & $\begin{array}{c}19,70 \pm \\
0,30\end{array}$ & $\begin{array}{l}21 \pm \\
0,22\end{array}$ & $\begin{array}{c}20,25 \pm \\
0,25\end{array}$ & $\begin{array}{l}21 \pm \\
0,15\end{array}$ & $\begin{array}{l}20 \pm \\
0,12\end{array}$ & $\begin{array}{c}21,2 \pm \\
0,48\end{array}$ & $\begin{array}{l}20 \pm \\
0,26\end{array}$ \\
\hline & $\sigma$ & 0,65 & 0,67 & 0,67 & 0,35 & 0,70 & 0,48 & 0,96 & 0,77 \\
\hline & $\mathrm{CV}$ & 3,10 & 3,41 & 3,22 & 1,75 & 3,34 & 2,41 & 4,51 & 3,85 \\
\hline \multirow{3}{*}{ 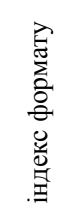 } & $\mathrm{M} \pm \mathrm{m}$ & $\begin{array}{c}101,2 \pm \\
0,12\end{array}$ & $100 \pm 0$ & $\begin{array}{c}101 \pm \\
0,26\end{array}$ & $\begin{array}{c}101,5 \pm \\
0,50\end{array}$ & $\begin{array}{c}101 \pm \\
0,06\end{array}$ & $\begin{array}{c}101 \pm \\
0,19\end{array}$ & $\begin{array}{c}101,8 \pm \\
0,25\end{array}$ & $\begin{array}{c}100 \pm \\
0,29\end{array}$ \\
\hline & $\sigma$ & 0,40 & 0 & 0,79 & 0,71 & 0,29 & 0,74 & 0,50 & 0,87 \\
\hline & $\mathrm{CV}$ & 0,40 & 0 & 0,79 & 0,70 & 0,29 & 0,74 & 0,49 & 0,86 \\
\hline \multirow{3}{*}{ 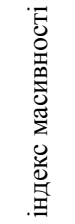 } & $\mathrm{M} \pm \mathrm{m}$ & $\begin{array}{c}119 \pm \\
0,93\end{array}$ & $\begin{array}{c}113,7 \pm \\
3,13\end{array}$ & $\begin{array}{c}118 \pm \\
0,76\end{array}$ & $\begin{array}{c}114,5 \pm \\
0,50\end{array}$ & $\begin{array}{c}118 \pm \\
0,76\end{array}$ & $\begin{array}{l}115 \pm \\
0,64\end{array}$ & $\begin{array}{l}116 \pm \\
3,03\end{array}$ & $\begin{array}{c}113 \pm \\
0,94\end{array}$ \\
\hline & $\sigma$ & 3,08 & 7,00 & 3,12 & 0,71 & 3,56 & 2,47 & 6,06 & 2,81 \\
\hline & $\mathrm{CV}$ & 2,60 & 6,15 & 2,31 & 0,62 & 3,01 & 2,15 & 5,22 & 2,49 \\
\hline \multirow{3}{*}{ 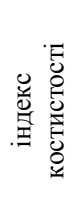 } & $\mathrm{M} \pm \mathrm{m}$ & $\begin{array}{c}12,8 \pm \\
0,16\end{array}$ & $\begin{array}{c}12,8 \pm \\
0,10\end{array}$ & $\begin{array}{c}12,6 \pm \\
0,10\end{array}$ & $\begin{array}{c}12,7 \pm \\
0,10\end{array}$ & $\begin{array}{c}12,7 \pm \\
0,07\end{array}$ & $\begin{array}{c}12,5 \pm \\
0,07\end{array}$ & $\begin{array}{c}12,6 \pm \\
0,21\end{array}$ & $\begin{array}{c}12,6 \pm \\
0,13\end{array}$ \\
\hline & $\sigma$ & 0,52 & 0,22 & 0,29 & 0,14 & 0,34 & 0,27 & 0,43 & 0,38 \\
\hline & $\mathrm{CV}$ & 4,04 & 1,72 & 2,31 & 1,11 & 2,69 & 2,13 & 3,38 & 3,00 \\
\hline
\end{tabular}

Аналіз таблиці 2, свідчить про те, що доросле поголів'я коней 3 сильним врівноваженим інертним та сильним неврівноваженим типами ВНД є досить крупними та близькими до рисистих порід за індексом формату (індекс 101), а молодняк - слабкого типу ВНД доволі костисті та масивні. Що ж стосується двох інших типів Коні сильного врівноваженого інертного та слабкого типів відповідають верховому типу породи.

Що стосується росту, то молодняк досліджуваних коней перевищує стандарт породи за всіма 4-ма показникам в групах сильного врівноваженого інертного, сильного неврівноваженого та слабкого типів ВНД на 5, 4, 8, 7, 16, 11, 1,25 та 2,2 см. У коней 3 сильним врівноваженим рухливим типом ВНД відбувається збільшення показників косої довжини, обхвату грудей та п'ястка на 1,8 та 0,7 см, а показник висоти в холці відповідає стандарту породи (163 см). 
Подільський вісник: сільське господарство, техніка, економіка
Podilian Bulletin: agriculture, engineering, economics

Таблиця 3 - Робоча продуктивність коней різного типу ВНД

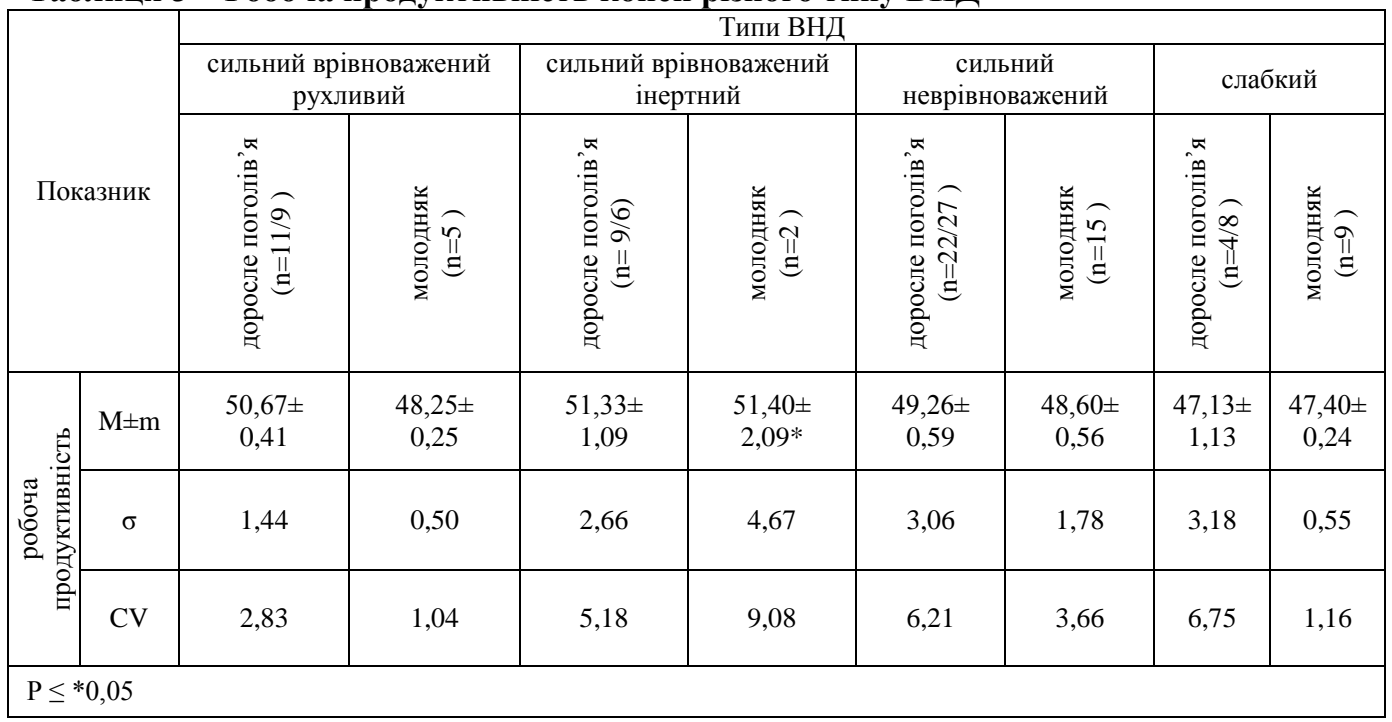

Аналіз даних таблиці 3 показує, що коні з сильним врівноваженим інертним типом ВНД мають найвищі показники робочої продуктивності. Проте, коні 3 сильним врівноваженим рухливим типом не сильно відстають за цим показником від попередньої групи. Найнижчі показники робочої продуктивності спостерігаються у коней зі слабким типом ВНД.

Таблиця 4 - Кореляційний зв'язок між екстер'єрними показниками та робочою продуктивністю коней

\begin{tabular}{|c|c|c|c|c|}
\hline Роботоздатність, міс. & Висота в холці, см & Коса довжина тулуба, см & Обхват грудей, см & Обхват п’ястка, см \\
\hline в 18 міс. & 0,339 & 0,607 & 0,452 & 0,600 \\
\hline в 24 міс. & 0,136 & 0,534 & 0,523 & 0,545 \\
\hline в 30 міс. & 0,214 & 0,203 & 0,564 & 0,418 \\
\hline в 42 міс. & 0,104 & 0,217 & 0,232 & 0,08 \\
\hline в 54 міс. і старше & 0,305 & 0,383 & 0,445 & 0,137 \\
\hline
\end{tabular}

Аналіз таблиці 4 показує на позитивний кореляційний зв'язок між робочою продуктивністю та основними промірами тіла коней. Найвищий кореляційний зв'язок у молодняку спостерігається у віці 18 міс. За косою довжиною тулуба та обхватом п'ястка. А найнижча - у віці 42 міс. За обхватом п'ястка

Висновки і перспективи. 1. Доросле поголів'я коней сильного врівноваженого інертного типу ВНД та сильного неврівноваженого досить крупні, є близькими до рисистих порід за індексом формату (індекс 101), а молодняк - слабкого типу ВНД доволі костисті та масивні. Що ж стосується двох інших типів - сильного врівноваженого інертного та слабкого, то вони відповідають верховому типу порід. 2. Коні сильного врівноваженого рухливого типу ВНД за живою масою та приростами спостерігається швидкий ріст що зумовлено більш швидким походженням всіх важливих процесів. 3. Отже коні сильного врівноваженого рухливого та інертного типів характеризуються кращими показниками росту та розвитку, а також робочою продуктивністю в зв'язку зі швидкість проходження основних нервових процесів, а також більш спокійним та 
врівноваженим темпераментом.

\section{Список використаних джерел}

1. Дорофеева Н. В. Оценка жеребцов-производителей лошадей верховых пород спортивного направления по качеству потомства по результатам испытаний молодняка в 2009 г. Дивово : ГНУ ВНИИ коневодства РСХА, 2010. 77 с.

2. Дорофеева Н. В. Оценка жеребцов-производителей лошадей верховых пород спортивного направления по качеству потомства по результатам испытаний молодняка в 2011 г. Дивово : ГНУ ВНИИ коневодства РСХА, 2012. 64 с.

3. Мельник Ю. Ф. Інструкція з бонітування племінних коней. Київ : Арістей, 2007. С. 8-19

4. Волков Д.А., Новиков А.А., Латка А.М. Краткая история, современное состояние и пути совершенствования украинской верховой породы лошадей. Государственная книга племенных лочадей украинской верховой породы. Київ. 2001. Т. 5. С. 14-38.

5. Гопка Б.М., Павленко П.М., Калантар О.А., Клок В.М. Конярство. Київ : Урожай, 1991. $231 \mathrm{c}$

6. Добрынин В. П. Выращивание молодняка лошадей. Москва : Сельхозиздат, 1954. 146 с.

7. Дрейпер Д. Лошади и уход за ними. Минск : Белфаксиздатгруп, 1997. 245 с.

8. Про затвердження нормативно-правових актів щодо бонітування племінних коней i племінного обліку в конярстві. Київ, 2003. URL : http://zakon.rada.gov.ua/laws/show/z0992-03 (дата звернення: 15.02.2019).

Дата надходження статті до редакиії: 29.04.2019 Рецензування 25.05.2019 Прийняття в друк: 27.06.2019

Slyusarenko Yu. L.

Assistant Professor

E-mail: slyusarenko.yulya@email.ua

Department of Technology of Production of Livestock Products

Zhytomyr National Agroecological University

Zhytomyr, Ukraine

\section{THE IMPACT OF HIGHER NERVOUS ACTIVITY TYPE ON WORK PRODUCTIVITY AND HORSE GROWTH}

\footnotetext{
Abstract

Estimation of working productivity of horses of sport breeds at an early age is of great selective and economic importance. The purpose of our research was to study the effect of the type of higher nervous activity on the formation of the level of working productivity of horses, basic measurements and live weight.

Methodology and source material. The research was carried out on the stock of horses of Ukrainian riding breeding plant PJSC "Rize-Maximko" ( $N=77)$.

The assessment of growth and development was carried out according to the following parameters: height in the neck, breast circumference, trunk length, trunk circumference and live weight.

Analysis of working productivity of horses was based on the results of factory tests in the farm.

In order to achieve this goal, conventional zootechnical methods were used. The origin of horses was determined on the basis of pedigree cards. The determination of the type of higher nervous activity was carried out according to the simplified methodology of the All-Russia Research Institute of Horse Breeding [4]. All data is statistically processed by the methods of variation statistics.

Results and discussion. For the analysis of exteriors, 77 horses of Ukrainian horse breed were selected, which was divided into 4 groups by the type of higher nervous activity. According to the results of the study of growth and development of horses. Adult livestock of horses with a weak type of higher nervous activity in height at the withers, oblique body length and chest circumference are likely to exceed the standard breed, respectively, at 2, 5 and $4 \mathrm{~cm}(P 0,01)$. The lowest indicators of height at the withers were observed in adult horses of 3 other groups $(164 \mathrm{~cm})$.
} 
Youngsters in measurements exceed the standard for 4 indicators in 3 groups (strong balanced inert, strong unbalanced and weak) respectively at 5, 4, 8, 7, 16, 11, 1.25 and $2.2 \mathrm{~cm}$. A horses with a strong, balanced motive type of higher nervous activity, exceed the standard for oblique length, chest and hemaggling by 1, 8 and $0.7 \mathrm{~cm}$.

Also, our research shows that horses with a strong, balanced inert type of higher nervous activity have the highest performance performance. However, horses with a strong, balanced, mobile type do not fall far short of this indicator from the previous group. The lowest indexes of work productivity are observed in horses with a weak type of higher nervous activity.

Keywords: horses, type of higher nervous activity, live weight, growth, indices, measurements.

\section{References}

1.Dorofeeva, N. V. (2010). Ocenka zherebcov-proizvoditelej loshadej verhovyh porod sportivnogo napravleniya po kachestvu potomstva po rezultatam ispytanij molodnyaka v $2009 \mathrm{~g}$. Divovo : GNU VNII konevodstva RSHA. [in Russ.]

2.Dorofeeva, N. V. (2012). Ocenka zherebcov-proizvoditelej loshadej verhovyh porod sportivnogo napravleniya po kachestvu potomstva po rezultatam ispytanij molodnyaka v $2011 \mathrm{~g}$. Divovo : GNU VNII konevodstva RSHA. [in Russ.] Ukranian]

3. Melnik, Yu. F. (2007). Instrukciya z bonituvannya pleminnih konej. Kiyiv : Aristej. [in

4.Volkov, D.A., Novikov, A.A., \& Latka, A.M. (2001). Kratkaya istoriya, sovremennoe sostoyanie i puti sovershenstvovaniya ukrainskoj verhovoj porody loshadej. Gosudarstvennaya kniga plemennyh loshadej ukrainskoj verhovoj porody. Kyiv. 2001. T. 5. [in Ukranian]

5.Gopka, B.M., Pavlenko, P.M., Kalantar, O.A., \& Klok, V.M. (1991). Konyarstvo. Kiyiv : Urozhaj. [in Ukranian] Russ.]

6.Dobrynin, V. P. (1954). Vyrashivanie molodnyaka loshadej. Moskow : Selhozizdat, 1954. [in

7.Drejper, D. (1997). Loshadi i uhod za nimi. Minsk : Belfaksizdatgrup. [in Russ.]

8.Pro zatverdzhennya normativno-pravovih aktiv shodo bonituvannya pleminnih konej i pleminnogo obliku v konyarstvi. Kiyiv, 2003. URL: http://zakon.rada.gov.ua/laws/show/z0992-03 (data zvernennya: 15.10.2003). [in Ukranian] 